\title{
EDUCAÇÃO PATRIMONIAL COM ADOLESCENTES DE BAIRROS PERIFÉRICOS DE BELÉM DO PARÁ COMO ESTRATÉGIA DE VALORIZAÇÃO DA MEMÓRIA CULTURAL
}

\section{Resumo}

Dariane Martins Montalvão

Universidade Federal do Pará darianemontalvao27@gmail.com

Helena Doris de Almeida Barbosa Universidade Federal do Pará hdoris@ufpa.br

O artigo apresenta resultados do projeto de extensão Educação Patrimonial a partir do Lazer e Recreação com os Adolescentes do Projeto Pro Paz nos Bairros, desenvolvido pela Faculdade de Turismo da Universidade Federal do Pará, em parceria com o Pro Paz nos Bairros. Tendo como objetivo a valorização do patrimônio histórico-cultural de Belém, como estratégia à efetivação da cidadania por meio da educação patrimonial, o projeto foi desenvolvido com 260 adolescentes em condição de vulnerabilidade social atendidos pelo Pro Paz. Baseado na tríade pesquisa, ensino e extensão, promoveu palestras, rodas de conversas, jogos, dinâmicas, exibição de filmes e visitas monitoradas ao patrimônio da cidade. Os questionários de sondagem, a observação direta e o feedback dado pelos integrantes permitiram compreender a realidade sociocultural desses jovens, bem como construir um novo olhar sobre o patrimônio de Belém e sobre o lazer na cidade.

Palavras-chave: Cultura. Educação Patrimonial. Lazer. Pro Paz nos Bairros.

\section{HERITAGE EDUCATION WITH TEENAGERS FROM PERIPHERAL DISTRICTS OF BELÉM DO PARÁ AS A STRATEGY FOR VALUING THE CULTURAL MEMORY}

\begin{abstract}
This article presents results of the extension project Heritage Education from Leisure and Recreation with Teenagers of the Pro Paz Program in the Neighborhoods developed by the College of Tourism of the Federal University of Pará with the state government program Pro Paz in the Neighborhoods. Actions were taken to promote the historical and cultural patrimony of Belém as a strategy for the effectiveness of citizenship through heritage education with 260 adolescents in a condition of social vulnerability and members of Pro Paz. Its effectiveness was based on the research triad, teaching and extension, which were agglutinated taking as a guideline ludic activities and technical visits to the cultural heritage of Belém. From the application of survey questionnaires and their feedback, dynamics, technical visits and direct observation, it's possible to understand the cultural reality of the young people who participated in the questionnaire, as well as the construction of a new look on the heritage of Belém.
\end{abstract}

Keywords: Culture. Patrimonial Education. Leisure. Pro Paz in the Neighborhoods.

\section{EDUCACIÓN PATRIMONIAL CON ADOLESCENTES DE BARRIOS PERIFÉRICOS DE BELÉM/PARÁ: UNA ESTRATEGIA PARA VALORAR LA MEMORIA CULTURAL DEL OCIO Y LA RECREACIÓN}

\footnotetext{
Resumen

El artículo presenta los resultados del proyecto de extensión "Educación Patrimonial de Ocio y Recreación con Adolescentes del Proyecto Pro Paz en los Barrios" desarrollado por la Facultad de Turismo de la Universidade Federal do Pará con el programa del gobierno estatal Pro Paz en los barrios. Tiene como objetivo la valorización del patrimonio histórico-cultural de Belém como estrategia para la efectividad de la ciudadanía, con la educación patrimonial desarrollada con 260 adolescentes en una condición de vulnerabilidad social que forman parte del ProPaz. Su efectividad se basó en la tríada de investigación, docencia y extensión, que se agruparon con conferencias, círculos de conversación, películas, juegos, dinámicas y visitas técnicas al patrimonio cultural de Belém. Desde la aplicación de cuestionarios de investigación y feedback, fue posible comprender la realidad cultural de los jóvenes que participaron del proyecto, así como la construcción de una nueva mirada acerca del patrimonio de Belém y del ocio en la ciudad.

Palabras clave: Cultura. Educación Patrimonial. Ocio. Pro Paz en los Barrios.
} 


\section{INTRODUÇÃO}

A questão patrimonial tem sido foco da atenção das mais diversas áreas do conhecimento. Tanto a sociedade civil quanto o Estado têm se mobilizado em ações de promoção e preservação do patrimônio coletivo. No entanto, ao mesmo tempo em que os governos (municipal, estadual e federal), enquanto dinamizadores de políticas públicas, desenvolvem importantes projetos em prol da proteção patrimonial, também são protagonistas do descaso com o patrimônio cultural, material e imaterial, em nível regional e nacional. Além disso, nem sempre os projetos e as iniciativas do Estado nesse setor atendem aos interesses/preferências da população local, principalmente em relação à democratização do espaço público, o que se constitui em vetor de desvalorização do bem patrimonial por ignorar as necessidades das sociedades contemporâneas.

O acesso aos espaços públicos é direito de todo cidadão, independentemente de sua situação socioeconômica. Porém, as barreiras sociais vigentes interferem no usufruto desses espaços, pois segregam a maior parte da população e os disponibilizam a determinados grupos privilegiados.

Os usuários privatizam o espaço através da ereção de barreiras simbólicas, por vezes invisíveis. O espaço público transforma-se, portanto, em uma justaposição de espaços privatizados; ele não é partilhado, mas, sobretudo, dividido entre os diferentes grupos. Consequentemente, a acessibilidade não é mais generalizada, mas limitada e controlada simbolicamente (SERPA, 2007, p. 36).

Na sociedade contemporânea, tal problema se estabelece de maneira mais contundente, já que a segregação espacial e a fragmentação dos espaços urbanos se apresentam como mosaicos irregulares (VASCONCELOS; CORREAA; PINTAUDI, 2013) ao criarem limites não somente em estabelecimentos particulares, mas também em espaços públicos.

O patrimônio cultural material da cidade de Belém, capital do estado do Pará,também se enquadra nesse contexto. Apesar de ser, em sua maioria, público, o acesso ao patrimônio local está atrelado à perspectiva da exclusão social e de interesses ideológicos. Segundo Vasconcelos (2013),esse processo pode ser caracterizado por uma segregação involuntária, porém coercitiva:ao serem excluídas da apropriação desses bens e desses espaços, as pessoas com baixo poder aquisitivo passam a agir com descaso em relação ao patrimônio público e a desenvolver perda da identidade cultural. 
Esse contexto gera um sentimento de não pertencimento cultural, corroborado pelas políticas culturais e de turismo, que muitas vezes criam "espaços” excludentes a serviço do lazer e do turismo. Santos (2012, p. 296), ao analisar a produção de espaços turísticos patrimoniais em Aracaju (SE) a partir da década de 1990, enfatiza que "os espaços enquanto destinos turísticos estão sendo criados e recriados, com a finalidade de satisfazer as exigências (sociais, econômicas, culturais e ambientais) da clientela". Nesse sentido, muitas vezes o morador não se insere nos espaços turistificados nem percebe o patrimônio local como um produto social coletivo, do qual faz parte e é responsável por ele.

Portanto, diante do cenário exposto, iniciativas que possam modificar essa perspectiva e democratizar o acesso ao patrimônio cultural se fazem necessárias. $\mathrm{O}$ acesso ao patrimônio deve ser efetivo não só para turistas e pessoas com alto poder aquisitivo, como para todo cidadão. $\mathrm{O}$ patrimônio, percebido como um instrumento de transformação da atual realidade de acesso ao espaço público/privado, ajuda a consolidar o vínculo do morador com a memória e história social, e pode torná-lo um cidadão consciente e zeloso por sua cidade.

De acordo com Boullón (2002, p. 109),

[...] depois de saber como são e como funcionam os elementos que integram o espaço turístico, é necessário identificar projetos, pensados não em si mesmos, mas como meio para melhorar o rendimento individual de cada elemento de forma coordenada, para que cada êxito parcial redunde em benefício do conjunto.

Sob essa perspectiva, foi desenvolvido o projeto de extensão Educação Patrimonial a partir do Lazer e Recreação com os Adolescentes do Projeto Pro Paz nos Bairros, realizado pela Faculdade de Turismo (FACTUR) da Universidade Federal do Pará (UFPA), durante o ano de 2014, com o apoio da Pró-Reitoria de Extensão da UFPA. O objetivo do projeto era a valorização do patrimônio histórico-cultural de Belém como estratégia à efetivação da cidadania, por meio da educação patrimonial e do lazer, realizado com adolescentes de 12 a 18 anos, participantes do programa Pro $\mathrm{Paz}^{1}$ nos Bairros. Buscou-se fomentar a noção e o sentimento de pertencimento cultural nesses

\footnotetext{
1 Programa do Governo do Estado do Pará criado pelo decreto estadual no .1 .046 , de 04 de junho de 2004, e organizado como política pública pela Lei estadual no. 7.773, de 23 de dezembro de 2013. Tem como objetivo atender jovens em estado de vulnerabilidade social, promovendo atividades interativas no entretempo não escolar (ocioso para alguns), para prevenir e reduzir os conflitos sociais.
} 
jovens perante o patrimônio cultural de seus bairros e da cidade, sem deixar de evidenciar os problemas enfrentados por eles no que diz respeito ao conhecimento e acesso a esse mesmo patrimônio.

Os polos selecionados para a realização das atividades foram Sacramenta, Terra Firme, Guamá e Mangueirão, todos localizados em bairros periféricos de Belém e marcados por uma trajetória de vulnerabilidade social, bem como ocupação desordenada de seus territórios por pessoas de baixo poder aquisitivo. O projeto foi operacionalizado por alunos voluntários da Faculdade de Turismo, e contou com a parceria institucional de outras entidades. A integração entre pesquisa, ensino e extensão foi a base das atividades desenvolvidas, o que viabilizou diversas ações como palestras, rodas de conversa, projeção de filmes, jogos e dinâmicas relativos às temáticas abordadas pelo projeto, os quais foram complementados com visitas monitoradas aos patrimônios da cidade, a fim de ressaltar a importância da preservação, conservação e valorização dos espaços culturais de Belém,concatenando-os com o patrimônio de seus bairros.

A partir das atividades realizadas, foi possível perceber que os adolescentes não se reconheciam como agentes de produção e manutenção cultural e, consequentemente, não mantinham uma afinidade efetiva com o patrimônio de seu bairro e do resto da cidade. Foram identificados também os principais problemas enfrentados por esse público, que se encontra em estado de vulnerabilidade social, e vislumbradas possíveis alternativas para estimular a percepção e o comportamento sadio desses jovens frente ao patrimônio local.

Entende-se a vulnerabilidade social

como uma condição das pessoas e das famílias relacionada aos seguintes elementos: a inserção e a estabilidade no mercado de trabalho, a debilidade de suas relações sociais e, por fim, o grau de regularidade e de qualidade de acesso aos serviços públicos ou outras formas de proteção social. Há ainda uma relação desta com o risco, pois as situações de vulnerabilidade social não prevenidas tendem a se tornarem uma situação de risco (ROMAGNOLI, 2015, p. 491).

Essa definição, um bom resumo daquela mais ampla preconizada por Kaztman et al. (1999, p. 19), ainda não é unânime e encontra variações aqui e ali, como a de Sevalho (2018), que defende a interdisciplinaridade do termo, relacionando-o ao sentido de fragilidade, o que, por sua vez, remete às origens dessa discussão, mais precisamente à década de 1970, quando vulnerabilidade era usada no 
âmbito dos desastres naturais ${ }^{2}$. Em estudo mais recente, Viegas $(2018$, p. 178) afirma que o processo de vulnerabilidade social se configura a partir da periferização e metropolização das cidades, que "[...] resguardam semelhanças entre si, tais como a ocupação de áreas à margem do centro da cidade e, porventura, a má condição ou inexistência de equipamentos urbanos”. Essa é, sem dúvida, a realidade enfrentada pelo público-alvo do projeto.

O público atendido pelo projeto é fruto desse processo de exclusão, cuja realidade cotidiana os coloca à margem do lazer, do turismo e da ação efetiva das políticas públicas. Por essa razão, todos os esforços se concentraram na tentativa de desenvolver uma experiência inovadora, que fortalecesse o capital cultural dos adolescentes em situação de risco - que muitas vezes desconhecem a história e memória cultural da cidade- agregando diferentes temas relacionados ao objetivo do projeto e aglutinando-os em torno da educação e da cidadania.

\section{TURISMO, CULTURA, LAZER E EDUCAÇÃO PATRIMONIAL COMO AGENTES DE MUDANÇA.}

O Turismo é percebido pelo senso comum como uma área de atuação elitista, associada exclusivamente a viagens, passeios e ao que vem de fora, o "estrangeiro"; no entanto, o caráter interdisciplinar dessa atividade tem permitido ao profissional da área desmistificar conceitos equivocados e preconceitos. Hoje o turismólogo pode atuar em diferentes setores que envolvam os serviços e a infraestrutura turística, seja dinamizando ou planejando ações para o turista - seja para recebê-lo, nesse caso na área da hospitalidade, seja para entretê-lo - ou para a população local, isto é, o núcleo receptor.

É comum nos trabalhos relacionados à atividade turística se pensar turismo unicamente vinculado à prestação de serviços "ao outro", ao turista. Todavia, Costa (2018, p. 28) enfatiza a possibilidade do fazer turístico a partir do morador local, porque "normalmente o turismo ocorre em um local que dispõe de um conjunto de empreendimentos complementares e concorrentes, o que supõe uma cooperação intrínseca", ou seja, ele inclui a participação da população anfitriã,

\footnotetext{
${ }^{2}$ Para aprofundamento da origem e desenvolvimento do conceito de vulnerabilidade social, cf.: MONTEIRO, S. R. da R. P. O marco conceitual da vulnerabilidade social. Sociedade em Debate, Pelotas, v. 17, n. 2, p. 29-40, jul./dez. 2011; CARMO, M. E. do.; GUIZARDI, F. L. O conceito de vulnerabilidade e seus sentidos para as políticas públicas de saúde e assistência social. Cadernos de Saúde Pública, v. 34, n. 3, p. 1-14, 2018; SCOTT, J. B.; PROLA, C. de A.; SIQUEIRA, A. C.; PEREIRA, C. R. R. O conceito de vulnerabilidade social no âmbito da psicologia no Brasil: uma revisão sistemática da literatura. Psicologia em Revista, Belo Horizonte, v. 24, n. 2, p. 600-615, ago. 2018.
} 
independentemente de sua ocupação espacial na cidade. Nesse sentido, o turismo deve superar a visão estritamente economicista depositada sobre a área, que até hoje limita o entendimento e as possibilidades dessa atividade e de seus profissionais; além disso, deve considerar a perspectiva do visitante e também do cidadão local (alteridade), dos próprios atores sociais, para uma ação efetiva e produtiva.

A ampliação das possibilidades de atuação do turismólogo permite sua participação em outros setores, no planejamento ambiental e cultural, por exemplo, o que tem sido ratificado em pesquisas e projetos, como o Educação Patrimonial a partir do Lazer e Recreação com os Adolescentes do Projeto Pro Paz nos Bairros. Esse projeto (dinamizado pelo princípio da questão cultural, pois não se pode trabalhar a educação patrimonial desarticulada do conceito de cultura) permitiu que acadêmicos de turismo pudessem efetivamente vivenciar a prática de conteúdos teóricos abordados nas disciplinas Patrimônio Cultural, Cultura Brasileira, Sociologia do Lazer, Lazer e Recreação, Antropologia do Turismo, entre outras. Ao serem retirados da sala de aula, os discentes puderam empiricamente examinar os conteúdos trabalhados exclusivamente em âmbito teórico, contribuindo com a formação pessoal e profissional desses alunos, que, de posse da teoria e da prática, estarão mais bem preparados para o mercado de trabalho e para a vida, a partir de uma perspectiva cidadã e comprometida com a sociedade da qual fazem parte.

O atrativo turístico (patrimônio cultural) são representações sociais no tempo e no espaço que fazem parte do cotidiano das cidades. A representação social é aquela produzida “[...] no senso comum por meio do pensar e do agir no dia a dia. Ao representar, os indivíduos têm como pano de fundo seus valores, identidades culturais, suas raízes e origens” (SIMONETTI; NASCIMENTO; CHAVES, 2018, p. 66). É na coletividade que as representações e identificações se constituem, pautadas na realidade vivenciada.

Nas palavras de Milton Santos (2014, p.81), “a cultura, forma de comunicação do indivíduo e do grupo com o universo, é uma herança, mas também um reaprendizado das relações profundas entre homem e o seu meio, um resultado obtido por intermédio do próprio processo de viver". Portanto, a cultura é responsável pela existência e, ao mesmo tempo, é a identidade de um povo. Para compreender uma identidade, deve-se, antes de tudo, perceber o contexto no qual ela é produzida, sentir-se, então, integrante desse contexto. A falta de compreensão e do sentimento de pertencimento ao lugar podem acarretar em descaso social, em indiferença e desvalorização das manifestações culturais e dos patrimônios públicos edificados. 
Dumazedier (2001, p. 285) enfatiza que "uma sociedade deve possibilitar a participação a um mínimo de valores comuns para poder viver e progredir, em lugar de destruir-se a si própria”. Entre esses valores, está o cultural, que, para se manter vivo, precisa que o sujeito se sinta membro do local, usufrua de suas produções e espaços com respeito e responsabilidade. E principalmente, perceba-se produto e agente da cultura, (re)construindo, assim, a memória cultural coletiva. Daí a importância em se trabalhar com jovens de áreas periféricas, pois, nesses lugares, a memória da história da cidade vem sendo esquecida ou desvalorizada - se lembrada, é apenas nos livros, não sendo mais vivenciada pela população - embora seja um bem primeiramente do morador local, seja da periferia ou não, e a ele deve ser transmitida, para depois ser apresentada ao turista, de forma espontânea ou induzida. No dizer de Rangel (2018, p. 55) “a memória apesar de referir-se ao passado incorpora um discurso que está em constante construção e reconstrução para responder [a]os problemas ou questões da actualidade". No entanto, muitas vezes os discursos produzidos sobre o patrimônio e a memória constituída não consideram e tampouco são voltados para os reais responsáveis por construí-los e/ou mantê-los - pelo contrário, esses são silenciados (RANGEL, 2018).

O turismo tem como uma de suas matérias-primas a cultura, portanto, pode se constituir em vetor de desmedramento ou regressão do processo de esquecimento dos costumes populares, ao ser capaz de "provocar a coesão da comunidade" e promover o seu encontro com um monumento, um prédio, uma ruína, representativos de sua localidade, mas esquecidos, e incentivar práticas de valorização de um determinado lugar. Desse modo, promove também "a revitalização do sentimento de pertencimento e, consequentemente, do reconhecimento social na dimensão comunitária, por meio das novas condições e funções sociais (re)definidas pelas adversidades e desafios cotidianos" (MANHÃES; ESTEVES, 2019, p. 120-121).

Destarte o turismo se entrelaça com a cultura. De acordo com Manhães e Esteves (2019, p.121) o turismo cultural envolve toda a produção cultural aglutinada em suas diferenças e semelhanças, marcas identitárias das sociedades humanas e por elas devem ser desfrutadas:

por meio do turismo cultural haveria não só o levantamento dos elementos estruturantes significativos, mas também, possibilitaria a reconstituição da identidade coletiva e da autoidentificação, e assim, o fortalecimento do sentimento de pertencimento por meio do reconhecimento social entre os membros da comunidade. 
O patrimônio cultural "implica em experiências positivas do visitante com o patrimônio histórico e cultural e determinados eventos culturais, de modo a favorecer a percepção de seus sentidos e contribuir para sua preservação” (BRASIL, 2010, p. 16); no entanto, o acesso a ele não deveria ser exclusividade de visitantes - realidade da maioria das cidades consideradas turísticas -, mas acessível a todos, principalmente moradores de onde está o patrimônio "turistificado" (CORBIN, 1989).

Em relação ao usufruto do patrimônio público de Belém, os moradores das áreas de estudo desta pesquisa ainda o consideram privilégio de pessoas com maior poder aquisitivo. Essa "elitização" do espaço se constitui em um problema para a construção da memória social, na medida em que todos, independentemente de nível econômico, moram na mesma cidade e vivem a herança da mesma história. Como exemplos desse processo de elitização do patrimônio em Belém ao longo do tempo, podem ser citados a Estação das Docas ${ }^{3}$, o Espaço São Jose Liberto ${ }^{4}$, a Casa das Onze Janelas $^{5}$ e o Museu de Arte Sacra ${ }^{6}$. Além desses, há aqueles que, embora acessíveis (geograficamente e financeiramente), ainda se mantêm distantes de grande parcela da população: o Theatro da Paz (edificado no período áureo da borracha na Amazônia, conhecido como belle époquē), que atualmente possui visita todos os dias, exceto aos domingos, mediante pagamento de um valor simbólico; e o cinema Olympia (o mais antigo em funcionamento da América Latina), que possui visita guiada gratuita e exibição de filmes todos os dias, às seis horas da tarde, aberta ao público. Os adolescentes atendidos pelo projeto nunca tinham visitado esses lugares.

Sob essa perspectiva, Campos (2017, p. 14) afirma que o conceito de patrimônio é construído ao longo da história, "como expressão política da memória"; afirma ainda, citando o professor e arqueólogo britânico Christopher Tilley", que o patrimônio "manipula identidades, que

${ }^{3}$ Complexo turístico edificado na orla de Belém, a partir da antiga Companhia das Docas do Pará (CDP).

${ }^{4}$ Local que outrora foi um hospital, um seminário, a cadeia pública e um presídio, hoje abriga um espaço cultural e o Museu de Gemas do estado.

${ }^{5}$ Entre os séculos XVIII e XIX, foi o Hospital Real e, posteriormente, teve funções militares. Hoje acolhe um museu para exposições temporárias e, em breve, hospedará o Instituto de Gastronomia Criativa.

${ }^{6}$ Um complexo arquitetônico construído no século XVII, que inclui a Igreja de Santo Alexandre. Lá fora instalado originalmente o Palácio Episcopal.

${ }^{7}$ Período de riqueza, prosperidade e modernização da Amazônia a partir do boom da borracha no século XIX (SARGES, 2002). Para Coelho, essa época é "entendida como manifestação da Idade de Ouro da cultura urbana da burguesia contemporânea, e cujos quadros tradicionais, como visto, remetem para a Paris do final do século XIX e começo do XX” (2011, p. 142).

${ }^{8}$ Para um detalhamento sobre o conceito de patrimônio na visão de Tilley, cf. TILLEY, Christopher. Identity, place, landscape and heritage. Journal of Material Culture, v. 11, n. 1-2, p. 7-32, 2006. 
são, como produtos da modernidade, alcançadas e não mais atribuídas". No entanto, na prática cotidiana, o que se percebe é uma exclusão e criação de verdadeiros "circuitos" ou guetos do lazer e entretenimento, e consequentemente da atividade turística - ou seja, "a expressão política” do patrimônio não alcança a maioria dos cidadãos, cujas identidades não estão representadas nesses espaços turistificados, nos quais a população da periferia de grandes cidades se sente ainda mais marginalizada.

A educação patrimonial visa também eliminar essa exclusão, além de ser uma ferramenta que possibilita, igualmente, mudar o cenário de descaso social em relação ao patrimônio cultural. Apesar de ter sua origem associada a espaços museais, a educação patrimonial pode ser utilizada, em outros contextos, em escolas, entidades e em ações de educação e cultura, pois consiste em "um trabalho educativo voltado à mobilização de saberes em torno do patrimônio, memória e da herança cultural, tanto em espaços da educação formal como informal” (SCIFONI, 2017, p. 6).Desse modo, permite-se a obtenção e assimilação de conhecimentos históricos, e expande-se o capital cultural dos sujeitos sociais, de forma a ser reconhecido o valor dos bens culturais e o estabelecimento de uma nova mentalidade acerca do patrimônio local.

[...] os processos educativos devem primar pela construção coletiva e democrática do conhecimento, por meio do diálogo permanente entre os agentes culturais e sociais e pela participação efetiva das comunidades detentoras e produtoras das referências culturais [...]. (BRASIL, 2014, p.19).

Entende-se, por conseguinte, a educação patrimonial como um canal de comunicação entre os diversos segmentos sociais que, direta ou indiretamente, estão associados ao patrimônio. $\mathrm{O}$ comprometimento da sociedade nesse processo, como copartícipe das ações do Estado, é fundamental, já que a educação patrimonial pode dinamizar ouso harmônico dos bens culturais, motivando os cidadãos a zelarem por eles, e a contribuírem com as demais esferas responsáveis por esses bens/espaços, combatendo o descaso corrente com o patrimônio da cidade.

Côrtes, Louzich e Bertolotoafirmam que o processo de educação patrimonial “deve partir da construção de um diálogo com a população, que demonstre a cada indivíduo a relação de pertencimento que cada um possui com a espacialidade[...]” (2018, p. 2). Trabalhar cultura, patrimônio e memória com adolescentes os faz se perceberem como autores de sua própria história e memória social, porque, quase sempre, eles se encontram em um estado de formação, e as 
informações adquiridas durante essa etapa da vida são diferenciais no desenvolvimento de seus caracteres.

Atualmente, o turismo cultural se fortalece com a disseminação da relevância da consciência patrimonial, que pretende alcançar a todos. Percebe-se que, para ocorrer a preservação e a valorização patrimonial, os objetivos não devem somente ser delineados para o visitante (turista). É necessário que o planejamento local se direcione além das razões econômicas, levando em consideração a participação direta dos atores sociais locais na sua execução, ou seja, há uma grande necessidade de sensibilizar a comunidade para a importância de manter viva a sua cultura e tradições, para que consigam transmiti-las naturalmente, sem artificialidades ou encenações.

Nesse sentido, o projeto Educação Patrimonial a partir do Lazer e Recreação com os Adolescentes do projeto Pro Paz nos Bairros desenvolveu suas atividades com base na educação patrimonial e nas vertentes do lazer e da recreação, pois, como afirma Dumazedier, o lazer "pode ainda criar novas formas de aprendizagem voluntária" (1973, p. 33). Considerando que o públicoalvo da pesquisa eram jovens de 12 a 18 anos, a ludicidade foi utilizada como ferramenta tanto de lazer como de aprendizagem, porque proporciona uma nova vivência no e com o bairro, a cidade e, claro, o patrimônio, afinal "[...] o lazer pode colaborar com o desafio de humanizar o homem, desenvolvendo competências e habilidades para que este possa compreender sua realidade, intervindo na mesma de forma consciente" (GOMES; PINTO, 2009, p. 52), além de facilitar a compreensão dos temas tratados no projeto.

Entende-se lazer como o

[...] conjunto de atividades gratuitas, prazerosas, voluntárias e liberatórias, centradas em interesses culturais, físicos, manuais, intelectuais, artísticos e associativos, realizados num tempo livre, roubado ou conquistado historicamente sobre a jornada de trabalho profissional e doméstico, e que interfere no desenvolvimento pessoal e social dos indivíduos (CAMARGO, 1986, p. 97).

Logo, se o lazer for planejado e implementado a partir dessas bases, poderá se tornar, de fato,em instrumento de inserção social.Todavia, frequentemente, a efetividade do lazer está relacionada unicamente a questões comerciais, ao status social ou poder aquisitivo, sem se preocupar com a ampliação do capital cultural do indivíduo ou em se conectar ao ambiente em que vive.

Há possibilidades concretas de se vivenciar o lazer, inclusive reconhecidas legalmente desde a Constituição Federal de 1988, ao definir os direitos sociais de todos os cidadãos: "São direitos 
sociais a educação, a saúde, a alimentação, o trabalho, a moradia, o transporte, o lazer, a segurança, a previdência social, a proteção à maternidade e à infância, a assistência aos desamparados, na forma desta Constituição" (BRASIL, 1988, art. $6^{\circ}$ - grifo nosso). Conforme os conceitos apontados por Dumazedier, o lazer constitui-se a partir de três funções: liberação e prazer; divertimento, recreação e entretenimento; e, por último, a função de desenvolvimento da personalidade. Particularmente nessa proposta, a ênfase é dada à terceira função, que "permite uma participação social maior e mais livre [...], oferece novas possibilidades de integração voluntária à vida de agrupamentos recreativos, culturais e sociais" (1973, p. 32), ou seja, viabiliza ao adolescente a perspectiva de agregar informações e tomar para si a possibilidade de atuar como sujeito ativo do resgate e manutenção da memória social local.

O tempo de lazer deve ser considerado privilegiado, por propiciar mudanças sociais, morais e políticas. Deve-se, portanto, destacar o quanto o lazer é importante socialmente, porque, em seu bojo, agrega valores culturais, incentiva o esporte e a cidadania, além de gerar um sentimento de pertença à cultura produzida pela sociedade ao longo da sua história. Souza (2010), ao citar as ideias

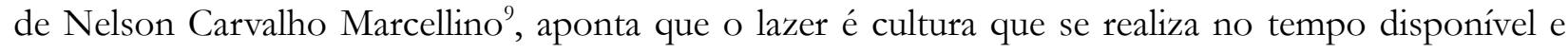
precisa ser estudado sob a ótica social, por ser um meio de propagação cultural. Entretanto, a sociedade ainda não reconhece a devida importância, tampouco dá o devido valor às práticas de lazer.

Desfrutar de momentos de lazer é direito de todo o cidadão. Por esse motivo, o projeto também pretendeu quebrar a barreira social erguida ao redor do lazer, trabalhando com os jovens conceitos de identidade, pertencimento, construção social, patrimônio, memória e do próprio lazer, com o intuito de sensibilizá-los a modificar suas percepções acerca desses temas, e estimulá-los a usufruir de seus direitos, a acessar o patrimônio púbico e praticar atividades de lazer sem colocar suas condições financeiras como obstáculo.

Desse modo, o projeto de extensão trabalhado pelos discentes de Turismo buscou aglutinar o lazer e a educação patrimonial, a fim de reforçar o resgate da identidade cultural dos jovens oriundos de espaços periféricos de Belém para democratizar e valorizar o espaço público patrimonial. O fio condutor das ações foram o lazer e a recreação, que proporcionaram a esses jovens reconhecer

\footnotetext{
${ }^{9}$ A visão de Marcellino em relação ao lazer pode ser conferida em: MARCELLINO, Nelson Carvalho. Laz̧er e educação. 2. ed. Campinas: Papirus, 1995.
} 
Educação Patrimonial com adolescentes de bairros periféricos de Belém do Pará

a importância dos bens culturais e naturais existentes na cidade, para que, consequentemente, pudessem (e ainda possam) valorizar também outros espaços, tornando-se conscientes do respeito à cultura local, nacional e mundial.

\section{A APLICABILIDADE DO PROJETO}

A tríade balizadora do projeto buscou articular ações de pesquisa, ensino e extensão ao longo das atividades. Inicialmente foi realizado um minicurso de capacitação (Figura 1), promovido pelo IPHAN (parceiro do projeto) aos alunos da Faculdade de Turismo (FACTUR), Campus Belém e Campus Universitário de Bragança. A intenção era não apenasa de qualificar os discentes como possíveis atores de dinamização cultural, mas também de prepará-los para estarem aptos a realizar atividades com o público-alvo. O minicurso ajudou a selecionar os voluntários que, com o bolsista e o coordenador, integraram a equipe de atuação do projeto.

As entidades que viabilizaram, por meio de parcerias, a realização do projeto foram a PróReitoria de Extensão da UFPA (PROEX), que cedeu uma bolsa de extensão durante um ano; o Instituto de Artes do Pará (IAP), entidade governamental responsável pelo Pro Paz nos Bairros; o IPHAN, que capacitou os voluntários (Figura 1) e forneceu kits educativos; e a Coordenadoria de Turismo de Belém (BELEMTUR), que forneceu material gráfico.

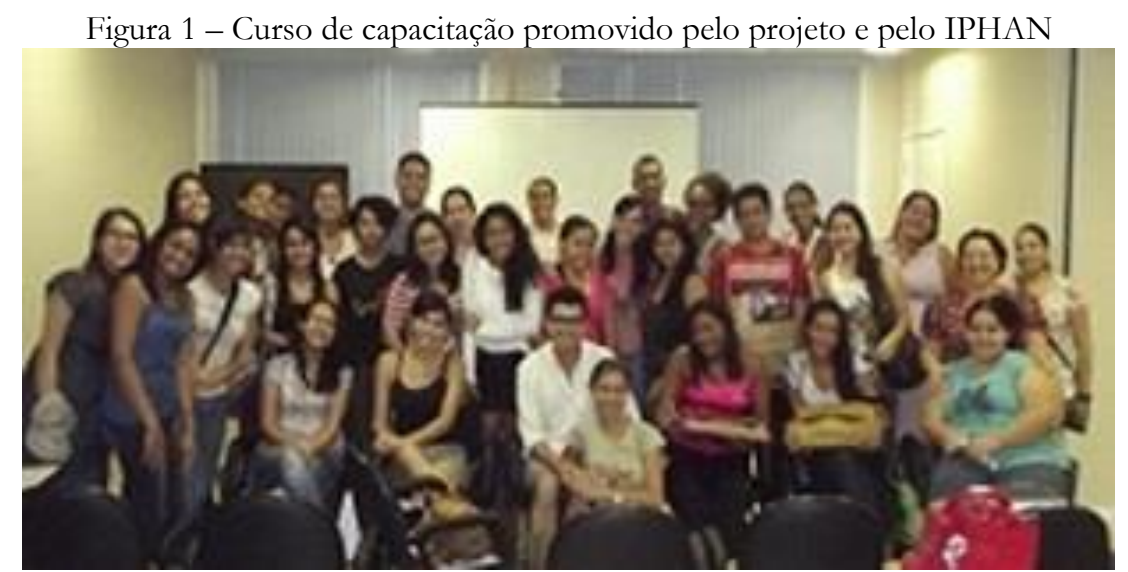

Fonte: Acervo do projeto (2014)

Posteriormente, foram realizadas reuniões entre os membros da equipe do projeto, a fim de estabelecer os parâmetros para a elaboração do material didático a ser trabalhado com os adolescentes, definir o cronograma, proceder à pesquisa bibliográfica e planejar as atividades práticas 
a serem executadas. Em seguida, as ações foram realizadas nos polos, atendendo às especificidades de cada um, sendo necessário reelaborar o material das palestras e dinâmicas de acordo com o perfil de cada grupo. As atividades eram efetivadas durante turno diferente ao das atividades escolares regulares dos alunos, ou seja, manhã e tarde.

Ocorreram quatro encontros em cada polo. Primeiro trabalhou-se no Pro Paz do Riacho Doce (que funcionava no Campus III ${ }^{10}$ da UFPA), no mês de setembro de 2014: duas semanas no turno da manhã, e as outras duas no turno da tarde. O segundo lugar atendido foi o Pro Paz da Terra Firme (que funcionava no campus da Universidade Federal Ruraldo Pará, UFRA),no mês de novembro, com a mesma dinâmica do polo anterior. No ano seguinte, finalizaram-se as atividades no polo Estádio Olímpico do Pará (EOP), o Mangueirão, no bairro do Parque Verde, e no polo Sacramenta, nos meses de março e maio, respectivamente, nos quais se utilizou a mesma linha trabalhada anteriormente, mudando apenas o conteúdo, já que era adaptado a cada bairro.

No primeiro encontro com os adolescentes foram aplicados testes de sondagem, com a finalidade de conhecer o perfil dos jovens e identificar as dinâmicas mais adequadas para trabalhar com eles. Os questionários tinham perguntas elaboradas para avaliar o conhecimento deles a respeito de conceitos básicos de patrimônio e lazer, bem como sua visão a respeito do bairro em que moram e a cidade de Belém, com enfoque no patrimônio.

Foram apresentados, por meio de dinâmicas variadas, os conceitos de identidade, memória e patrimônio (material, imaterial e natural), ensinando noções básicas acerca dessas temáticas, para que eles fossem provocados a debater e a perceber a sua função e papel em relação a esses conceitos. Expôs-se também a história dos bairros onde moravam, para levá-los a perceber a importância do lugar onde vivem, e a valorizar esses espaços, que muitas vezes se encontram em um estado de abandono físico e social. Um dos resultados alcançados foi desconstruir na cabeça dos adolescentes a hierarquização de bairros que lhes é imposta, conscientizando-os de que todos são frutos de relações sociais e pertencentes à mesma cidade e detentores de patrimônios.

No terceiro momento, apresentaram-se os contextos históricos referentes aos principais patrimônios materiais, imateriais e naturais de Belém, mostrando-lhes a importância e a necessidade de cuidar desses bens. Buscou-se fazer com que esses adolescentes se sentissem atores da história de Belém, e agentes responsáveis pela preservação de seus bens coletivos. Todas as atividades (Figura 2)

\footnotetext{
${ }^{10}$ Também conhecido como Setor Saúde, está localizado na Cidade Universitária Prof. José da Silveira Netto (Campus
} Belém), no bairro da Terra Firme, em Belém. 
foram pautadas pela ludicidade e tinham o intuito de despertar o interesse em conhecer, valorizar e propagar a informação para seus familiares e amigos.

Figura 2 - Operacionalização do projeto em sala de aula

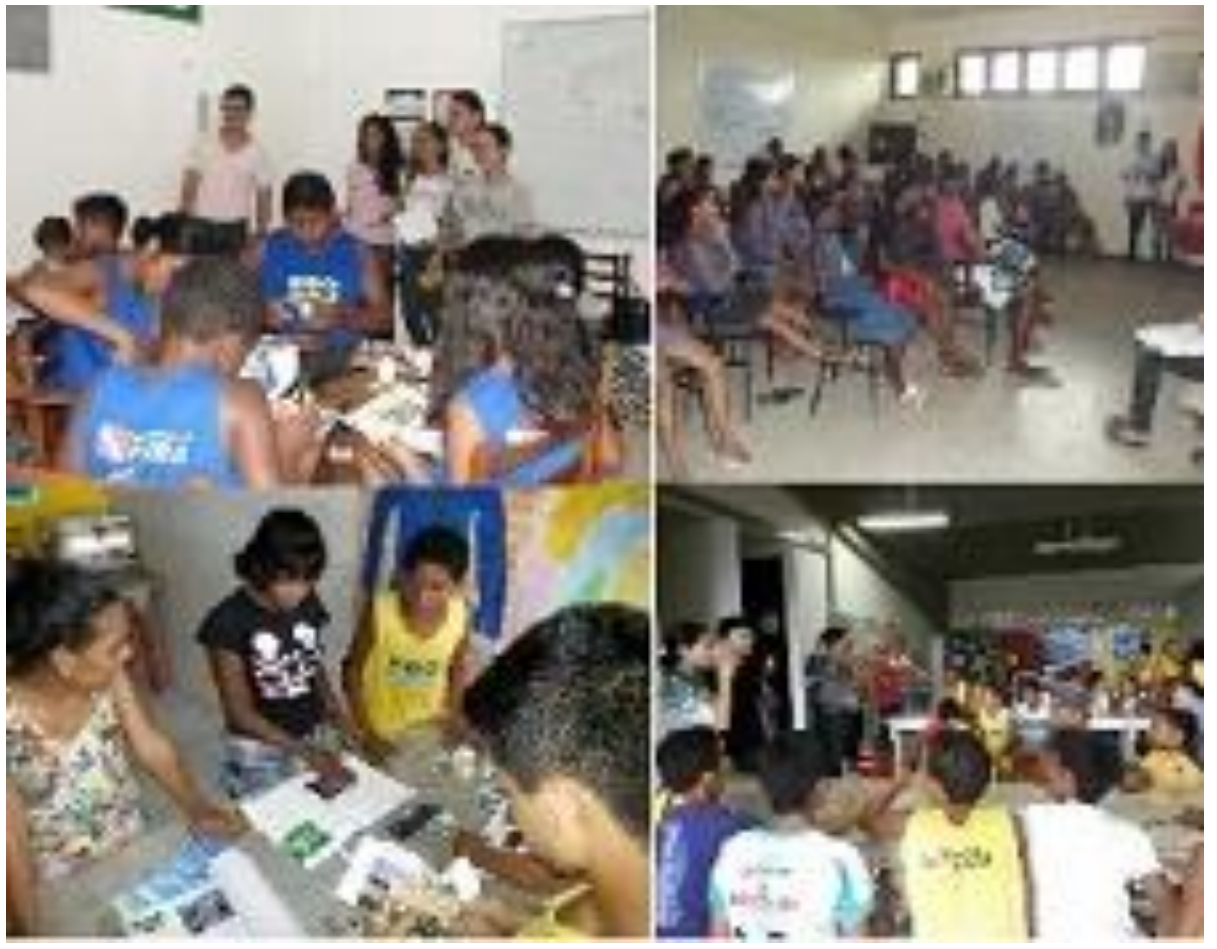

Fonte: Acervo do projeto

Finalizando as atividades, foram realizadas as visitas técnicas a patrimônios públicos relevantes da cidade de Belém, escolhidos pelos próprios jovens, que não conheciam esses espaços. Os patrimônios escolhidos foram Complexo Feliz Luziânia, Theatro da Paz, Palacete Bolonha, Museu de Arte do Estado do Pará e Museu de Arte de Belém - alguns se repetiram conforme o interesse dos adolescentes. As visitas eram monitoradas: o patrimônio era apresentado em sua estrutura, história e importância, sempre tentando articular o conteúdo anteriormente trabalhado nas dinâmicas em sala com o que estava sendo visto/visitado (Figura 3). Essa etapa se configurou como o ponto principal do projeto: tudo o que foi dinamizado culminava com as visitas técnicas, nas quais fora possível receber o feedback dos jovens pela reação deles no contato direto com o patrimônio cultural. 


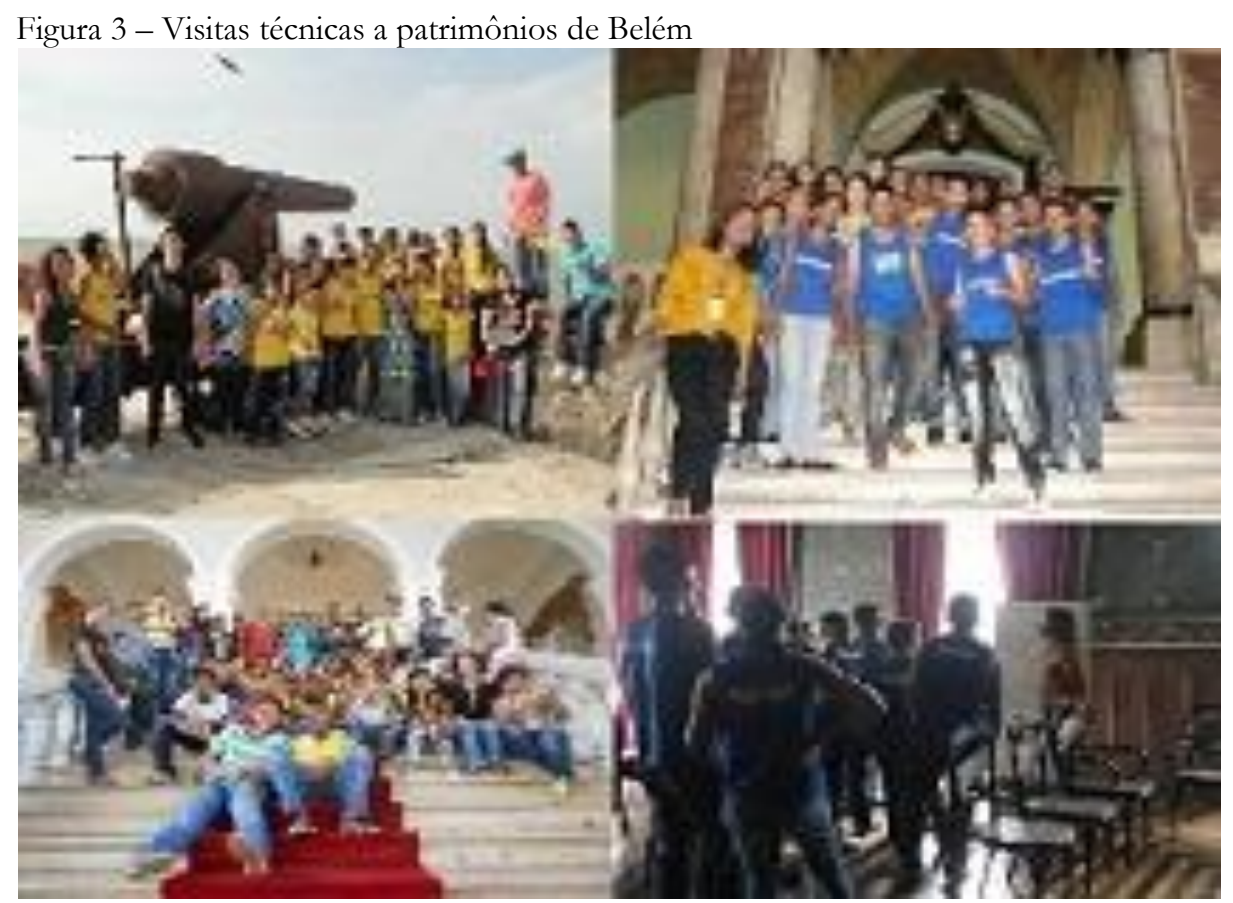

Fonte: Acervo do Projeto

Os jovens atendidos pelo projeto vivem (ou viviam até o encerramento das atividades) em situação de vulnerabilidade social, a começar pelo fato de residirem em locais onde a violência é constante e as oportunidades de acesso a informações escassas, além de pertencerem ao grupo de indivíduos apontado como principal responsável pelo processo de vandalização do patrimônio cultural. Em contrapartida, esses mesmos jovens são reconhecidos como elementos multiplicadores de informações no seu contexto familiar e social, o que torna a iniciativa ainda mais inovadora e relevante, também por considerar o espaço onde eles moram, que apresenta dinâmicas pautadas por problemas sociais, provenientes do processo de expansão desordenada dos centros urbanos, que gera e, ao mesmo tempo, cerceia as áreas em situações de exclusão, marginalização e condições de risco social, limitando aos seus moradores as possibilidades de se perceberem e atuarem como sujeitos sociais plenos.

Ampliar o conhecimento e incentivar o pensamento crítico são fatores importantes para mudanças sociais. $\mathrm{O}$ fato desses jovens conhecerem mais sobre seu bairro, a cidade em que moram, sua cultura e a possibilidade de repassarem esse conhecimento adiante é um passo relevante em sua formação cidadã. É a materialização efetiva de um dos objetivos do projeto, aproximá-los dos patrimônios e contribuir para o empoderamento deles, pautado na informação, na conquista da cidadania e da acessibilidade. 
Colaborar na formação acadêmica dos discentes envolvidos no projeto e, principalmente, despertá-los para a importância da dimensão da cidadania a partir da cultura e da educação também se constituem em objetivos alcançados. Esses sujeitos se aglutinaram primeiramente pelo saber e, em seguida, pelo interesse na formação e consolidação do capital cultural ${ }^{11}$, levando-os a compreender o valor da cultura em geral, por meio do respeito e pela quebra de barreiras sociais e econômicas, tendo, assim, a oportunidade de se perceberem agentes sociais de proteção do patrimônio local.

\section{RESULTADOS E DISCUSSÕES}

Os questionários de sondagem aplicados no primeiro encontro com os adolescentes revelaram que a maioria dos jovens não conhecia a história do seu bairro nem a de Belém, apesar de terem nascido na cidade. Detectou-se também que eles não visitavam os espaços patrimoniais públicos por diversos motivos, desde a falta de interesse até o pensamento de que determinado local era "só pra quem tem dinheiro" ou "só pra turista", referendando assim as chamadas barreiras sociais, fruto do que Coriolano (2004) denomina contradições entre capital e trabalho.A democratização dos espaços patrimoniais para o lazer se constitui ainda um desafio a ser superado, mormente para o usufruto das populações da periferia de Belém: o projeto se apresentou como uma alternativa de aproximação dos jovens com o patrimônio e a memória local, por serem poucas as oportunidades deles em ter contato com os registros e símbolos da história da cidade.

Ainda de acordo com os resultados dos questionários, 85\% dos 260 adolescentes não sabiam sequer o que era patrimônio - nota-se, pois, a falta de informação em relação ao conceito de bens coletivos e públicos. Nesse sentido, um dos motivos para esses jovens não valorizarem o patrimônio é o desconhecimento total ou parcial do real significado dessa palavra, que está diretamente ligado à cultura: não tinham como reconhecer, portanto, a importância dele. Os 15\% que afirmaram saber o que era responderam superficialmente, tendo uma pequena noção do significado; desses, a maioria apontou o patrimônio como "coisas importantes para as pessoas" ou "coisas antigas" - na realidade, como se conclui, os jovens não identificam o que de fato estabelece as bases conceituais da categoria patrimônio.

\footnotetext{
11 Utilizado no sentido de Bourdieu (1982), que o compreende como valores culturais transmitidos de geração a geração e
} que pode ou não ser incorporado pelo indivíduo. 
Educação Patrimonial com adolescentes de bairros periféricos de Belém do Pará

Vale ressaltar que os adolescentes, em sua maioria, cursavam o ensino fundamental; logo, percebe-se a carência do ensino formal em trabalhar, na estrutura curricular, a cidade. Geralmente, são enfocados pelas escolas apenas questões históricas, mas de outros lugares; o lugar onde os alunos moram é esquecido, ou, quando lembrado, é de maneira superficial, não se leva em conta a questão da cultura enquanto parâmetro de análise. O resultado é a valorização de outras culturas em detrimento da local, o que suscita nos adolescentes o preconceito com a própria cidade e seus bens históricos - crescem contaminados por essa mentalidade e tornam-se adultos hostis com seu meio.

Em relação ao lazer, 65\% dos adolescentes apontaram não saber o seu que significava, e 85\% afirmaram que, em seus bairros, não há espaços de lazer. Percebeu-se que os adolescentes têm uma noção do que seria a prática do lazer, baseados apenas em sua vivência empírica. Os que responderam saber o que seria o lazer, a maioria o resumiu a "brincar" e "passar tempo com a família”,ou seja, a prática do lazer realizada por esses jovens é espontânea e eles desconhecem a existência de atividades programadas de lazer no local onde moram.

Outra questão que chamou atenção foi a constância - ou melhor, a falta dela - com que os jovens frequentavam os patrimônios públicos: 94,5\% responderam os terem visitado "poucas vezes"; ao se pedir a justificativa de tal frequência, a maioria afirmou não os conhecerem ou, como vimos, acreditar que são espaços reservado a turistas.Entende-se, então, que o senso comum influencia o pensamento desses jovens, motivo pelo qual não frequentamos espaços públicos e, em muitos casos, não valorizam os bens locais.

Para desmistificar essa percepção, o projeto se preocupou em repassar informações de acesso a esses bens, incluindo a narrativa da história de cada patrimônio e avisando de que maneira os adolescentes podem visitar, com familiares e amigos, esses espaços ao longo da semana, sem custos. O projeto também levou esses jovens a pontos turísticos escolhidos por eles, a fim de mostrar-lhes como e por que são produtos culturais; lugares e edificações que, ao longo do tempo, tiveram suas funções modificadas pela dinâmica social, caracterizando-se hoje como patrimônios públicos.

As atividades realizadas nos quatro polos supracitados atenderam em média dez zonas e bairros considerados periféricos na cidade de Belém: Riacho Doce, Guamá, Terra Firme, Tucunduba, Mangueirão, Coqueiro, Sacramenta, Parque Verde, Marambaia e Bengui. Notou-se que o projeto despertou nos adolescentes o interesse em conhecer a história do bairro onde moram (ou moravam) e da cidade que habitam; também os motivou a contribuir com as atividades de forma participativa, 
indagando, respondendo e contando histórias de familiares, ajudando a fomentar o conhecimento trabalhado. O projeto não atingiu 100\% do seu público, mas obteve êxito ao sensibilizar a maioria quanto às temáticas propostas, e ao motivar os jovens a colocar seus conhecimentos em prática e serem um veículo de disseminação do conhecimento aos seus amigos e familiares.

A execução das atividades a partir do prisma do lazer facilita a aprendizagem dos adolescentes, tornando os encontros mais dinâmicos e estimulantes. Pela ludicidade, o jovem pode ser mais cativado e levado a apreender de forma descontraída - lembrando que foram realizadas atividades de colagem, gincanas, exibição de vídeos, além de palestras interativas para possibilitar a troca de sabres e experiências entre os voluntários e os adolescentes.

O projeto possibilitou aos jovens o contato com a prática transversal do ensino escolar, com conteúdos locais ligados à cultura, que são valiosos para a formação cidadã, porém não são inseridos efetivamente no currículo escolar dos jovens de ensino fundamental e médio. A imersão interdisciplinar da cultura local na estrutura formal de ensino possibilita o crescimento individual do discente a partir das noções de cultura material e imaterial, patrimônio, memória, cidadania, interligados a práticas de lazer, para estimular o sentimento de pertença, valorização e democratização dos espaços públicos. Os adolescentes puderam ter uma nova experiência, um novo olhar sobre sua realidade e seu município, mas o caminho não está concluído, eles devem ser estimulados a buscar novos conhecimentos.

A ausência da educação patrimonial na formação dos adolescentes é um dos caminhos para o esquecimento e desvalorização da cultura. A memória cultural não fortalecida, com o passar do tempo, deixará de fazer parte da vida desses jovens e, quando adultos, não se perceberão agentes de cultura. Nesse sentido, projetos que trabalhem o presente tema são fundamentais para que esse cenário seja modificado. Cabe também ao poder público o incentivo e viabilização de ações que

possam fazer despertar nos jovens o interesse pela cultura, o sentimento de pertencimento com relação ao patrimônio local, e a consciência de se tornarem produtores e gestores culturais.

\section{REFERÊNCIAS}

BRASIL. Ministério do Turismo. Turismo cultural:orientações básicas. 3. ed. Brasília: Ministério do Turismo, 2010.

BRASIL. Instituto do Patrimônio Histórico e Artístico Nacional. Educação patrimonial: histórico, conceitos e processos. Brasília: IPHAN, 2014.Disponível em: 
Educação Patrimonial com adolescentes de bairros periféricos de Belém do Pará

http://portal.iphan.gov.br/uploads/publicacao/EduPat_EducacaoPatrimonial_m.pdf. Acesso em: 02 out.2016.

BRASIL. [Constituição (1988)]. Constituição da República Federativa do Brasil de 1988. Brasília,DF: Presidência da República, [2016]. Disponível em:

http://www.planalto.gov.br/ccivil_03/constituicao/constituicao.htm. Acesso em 10 out. 2016.

BOULLÓN, R. C. Planejamento do espaço turístico. Bauru: EDUSC, 2002.

BOURDIEU, P. A economia das trocas simbólicas. São Paulo: Perspectiva, 1982.

CAMARGO, L. O. L. O que é laz̧er. São Paulo: Brasiliense, 1986. (Primeiros Passos, 172).

CAMPOS, Y.D.S. de. Percepção do intangivel: entre genealogias e apropriações do patrimônio cultural imaterial. Goiânia: Arraes, 2017.

COELHO, G. M. Na Belém da belle époque da borracha (1890-1910): dirigindo os olhares.

Escritos,Rio de Janeiro, v. 5, n. 5, p. 141-168, 2011.

CORBIN, A.Território do vazio?a praia e o imaginário ocidental. Tradução de Paulo Neves. São Paulo: Companhia das Letras, 1989.

CORIOLANO, L. N. M. T. Turismo: prática social de apropriação e de dominação de territórios. In: LEMOS, A. I. G. de;ARROYO, M.; SILVEIRA, M. L. (org.). América Latina: cidade, campo e turismo. São Paulo: CLACSO, 2006. p. 367-378.

CÔRTES, M.L.; LOUZICH, K.M.D.;BERTOLOTO, J.S.Cidade, patrimônio, arte e educação: a arteeducação como ferramenta de conscientização patrimonial e salvaguarda da identidade cultural da cidade.In: SEMINÁRIO DE INICIAÇÃO CIENTÍFICA, 9.,2018. Mato Grosso. Anais eletrônicos [...]. Mato Grosso: Unopar: Uniderp: Unic: Anhanguera, 2018. Disponível em: https://repositorio.pgsskroton.com.br/bitstream/123456789/22449/1/UNIC\%20\%20Mara\%20Lopes\%20Cortes.pdf. Acesso em: 15 dez. 2019.

COSTA, H. A. Olhares sobre a cooperação empresarial entre pequenas empresas em destinos turísticos: reflexões e aprendizados de pesquisa. In: NASCIMENTO, E.P.; COSTA, H. A. (org.).Turismo e sustentabilidade: verso e reverso. Rio de Janeiro:Garamond, 2018. p. 25-40.

DUMAZEDIER, J.Laz̧er e cultura popular. São Paulo: Perspectiva, 1973. (Debates: C. Sociais).

DUMAZEDIER, J. Lazere cultura popular. São Paulo: Perspectiva, 2001. (Debates: C. Sociais).

GOMES, C.; PINTO, L.M. S. M. O lazer no Brasil:analisando práticas culturais cotidianas, acadêmicas e políticas. In: GOMES, C.et al. (org.). Laz̧er na América Latina:tiempolibre, ocio y recreación en Latinoamérica. Belo Horizonte: Editora UFMG, 2009. p. 39-76. 
Educação Patrimonial com adolescentes de bairros periféricos de Belém do Pará

KAZTMAN, R.; BECCARIA, L.; FILGUEIRA, F.; GOLBERT, L.; KESSLER, G. Vulnerabilidad, Activos y Exclusión Social en Argentina y Uruguay. Santiago: Oficina Internacional delTrabajo; Fundación Ford, 1999. (Documento de Trabajo 107; Serie Exclusión Social - Mercosur).

MANHÃES, M.C.; ESTEVES, J.C.R. O turismo cultural, territorialidade e cultura local da comunidade pesqueira artesanal de Arraial do Cabo. Revista Iberoamericana de Turismo - RITUR, Penedo, v. 9, número especial, p. 114-122, mar. 2019.

RANGEL, M. M. Omissões do património cultural na Fortaleza de Maputo na perspectiva dos discursos dos visitantes. Embondeiro,Maputo (Moçambique), n. 2, p. 49-56, out. 2018.

ROMAGNOLI, R. C. Problematizando as noções de vulnerabilidade e risco social no cotidiano do SUAS. Psicologia em Estudo, Maringá. v. 20, n. 3, p.449-459, jul./set. 2015.

SANTOS, C. A. de J. Produção e consumo de espaços turísticos: apropriação de espaços públicos de lazer e turismo em Aracaju/SE. In: CORIOLANO, L. N.; VASCONCELOS, F. P. (org.). Turismo, território e conflitos imobiliários. Fortaleza: EdUECE, 2012. p. 283-298.

SANTOS, M.O espaço do cidadão. 7. ed. São Paulo: Editora da Universidade de São Paulo, 2012. (Coleção Milton Santos, 8).

SARGES, Maria de Nazaré. Belém: riquezas produzindo a Belle-Époque (1870-1912). Belém: PakaTatu, 2002.

SCIFONI, S. Desafios para uma nova educação patrimonial. Revista Teias, v. 18, n. 48, p. 5-16, jan./mar. 2017.

SERPA, A.O espaço público na cidade contemporânea.São Paulo: Contexto; Salvador: EDUFBA,2007.

SEVALHO, G. O conceito de vulnerabilidade e a educação em saúde fundamentada em Paulo Freire. Interface. Botucatu, v. 22, n. 64, p. 177-188, maio 2018.

SIMONETTI, S.R.; NASCIMENTO, E.P. do; CHAVES, M. P.S.R. Representações sociais e turismo comunitário: um estudo em comunidades de áreas protegidas no Amazonas. In: NASCIMENTO, E.P.do; COSTA, H. A. (org.). Turismo e sustentabilidade: verso e reverso. Rio de Janeiro: Garamond, 2018. p. 65-91.

SOUZA, T.R. de. Lazer e turismo: reflexões sobre suas interfaces. SEMINÀRIO DE PESQUISA EM TURISMO DO MERCOSUL,6., 2010, Caxias do Sul. Anais eletrônicos [...]. Caxias do Sul: UCS, 2010. p. 1-15. Disponível em:

https://www.ucs.br/ucs/tplSeminTur2010/eventos/seminario_de_pesquisa_semintur/anais/gt11/a rquivos $/ 11 /$ Lazer $\% 20 \mathrm{e} \% 20$ Turismo $\% 20$ Reflexoes $\% 20$ Sobre $\% 20$ Suas $\% 20$ Interfaces.pdf. Acesso em: 20 dez. 2019.

VACONCELOS, P. de A.; CORRÊA, R. L.; PINTAUDI, Silvana Maria. Introdução. In: VACONCELOS, P. de A.; CORRÊA, R. L.; PINTAUDI, S. M. (org.). A cidade contemporânea:segregação espacial. São Paulo: Contexto, 2013. p. 7- 15. 
Educação Patrimonial com adolescentes de bairros periféricos de Belém do Pará

VACONCELOS, P. de A. Contribuição para o debate sobre processos e formas socioespaciais na cidade. In: VACONCELOS, P. de A.; CORRÊA, R. L.; PINTAUDI, S. M. (org.). A cidade contemporânea: segregação espacial. São Paulo: Contexto, 2013. p. 17-38.

VIEGAS, D. H. Os arquitetos e a cidade: história e memória da Região Metropolitana de Porto Alegre. In: GRAEBIN, C.M.G.; BERND, Z.;SILVA, M.L. B. da. (org.). Memória social e cidades: práticas, representações e imaginários. Canoas: Unilasalle2017. p. 173-190.

Recebido em: 26/04/2019

Aceito em: 27/02/2020 